\title{
Teaching about \\ Food, Sex and \\ Gender in \\ the Classroom
}

\section{ESSAY}

\section{BY RiCHARD WILK}

\section{Abstract}

\section{Teaching about Food, Sex and Gender in the Classroom}

In this essay Richard Wilk shares his experience with teaching a course on food, sexuality and gender and the challenges it proved to provide during the semester: not only was finding literature and putting the syllabus together demanding tasks, there was also a series of rather uncomfortable, affective moments in the class during the semester. Wilk presents perspectives on teaching the theme of food, sexuality and gender and highlights the importance of current discussions about gender and sexuality in contemporary food studies.

\section{KEYWORDS}

Gender, sexuality, food, teaching, academial

kon, seksualitet, mad, undervisning, akademia 


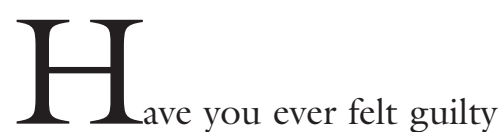
about something you ate, maybe an indulgence that you knew was bad for you? Does food ever make you feel romantic or amorous? Have you ever worried about what you should eat on a date? Food goes right at the center of the way we experience and perform gender, and eating is deeply connected both physically and emotionally with our sexuality and romantic relationships. We even use food words to describe sexual acts, and sing about buns, candy sticks, and bearded clams.

At some point in teaching any University course on food, gender is going to enter the conversation, either explicitly or implicitly. Conversely, in a good course in gender studies, food may be a silent presence in the classroom, particularly when the discussion turns to body image. This is because food is profoundly gendered in every culture, in all of history and human evolution, and in every corner of the contemporary mediascape. Anthropologists have studied how many cultures forbid or prescribe specific foods according to gender and life stage, and many are believed to affect potency or fertility. The language of food is full of sexual metaphor and meaning, providing the basis for double-entendre, satire and humor. The connection between food and sex is celebrated in song and other performing arts. For these reasons, whenever you teach about food, gender and sexuality are never far behind - and in a consumer culture they are often right out front. In the USA the mass media is saturated with gender and sexual themes connecting directly with food, and with images now defined as 'food porn.'

My decision to develop a new class on Food, Sex and Gender (FSG) at Indiana University in the spring of 2010 was prompted by my experiences separately teaching classes on gender and consumer culture, and on food and culture. Nevertheless it seemed like a real challenge to design a course on food for students in the Indiana University department of Gender Studies, where most of the students had no background in food studies or anthropology. I wondered if there would be enough student interest among a group who generally frowned on traditional North American gender roles that make food into 'women's business.' Food preparation is after all one of the most highly gendered tasks in EuroAmerican society, and food advertising is full of exploitative sexual and erotic imagery. I also wondered if there was enough real subject matter to fill a semester, and if I would find enough books and articles to use as class readings, and to inform my own approach to the topic. I need not to have worried about the first issue, since the class filled up in the first few days of registration, and there was a substantial waiting list. Students were thoroughly engaged in the class, and found everything easy to relate to their own lives. As I worked on a syllabus I quickly found that I wanted to cover far more topics and issues than I could fit in a single semester, but I also discovered that there was very little social science research or publication on some of those topics.

The process of course design was actually energized by the missing literature - it led me to good questions about selective blindness and the marginalization of many gendered topics. The gaps also meant that the class was often exploring unknown territory so the students' own research and writing was a process of real discovery. What I did not anticipate though, was the connection between food, sex and gender becoming so intimate and personal, which meant that classes were often charged with an emotional weight I had never before sensed in the classroom. 
SENSES, SENSITIVITY

AND EMBODIMENT

Advertising no longer hides assumptions about gender and sex or uses them gingerly, indirectly and with subtlety. Instead todays advertisers loudly and overtly use sex and gender to sell, and gender plays a key role in the process of 'segmentation' 2 in modern marketing. This leads to absurdities like separate bottled water for men, women, boys and girls (there are several websites devoted to unnecessarily gendered products $^{3}$ ). A constant bombardment of gendered advertising and marketing helps create a consumer culture where it just seems 'natural' that men and women should need different toothbrushes, that women enjoy changing diapers, and that men love red meat while women prefer white.

Because of the close relationship between these topics, almost every course on food must deal in some way with gender and sexuality, if only because social roles in food production and preparation are so highly gendered in developed countries. Classroom discussion of sex and gender in a food studies course become awkward and personal for both teachers and students, particularly on topics like gender roles in cooking, body images, the boundaries between 'normal' and deviant eating, and the way emotional states can be expressed or internalized through food.

This sensitivity can also be a very direct way to broaden students understanding of the social and cultural roles of food in our lives. Even more importantly, discussions of gender and sexuality can help forge a close relationship between the often abstract and exotic examples in readings, and the students own daily experiences. It builds a sense of history, and punctures easy assumptions about what is 'natural' for human beings. This is why it is worth taking the time and effort to engage with sex and gender in the food studies classroom.

Before I developed my FSG class in
2010 I taught broader undergraduate classes on gender and consumer culture, including a class I called 'Extreme Masculinities'. This gave me some experience in teaching sensitive and personal topics, particularly as the only straight white male in a very diverse gender studies faculty. But food turned out to be more highly charged than other kinds of material culture, particularly because of the associations between food, weight and sexuality.

The first time I taught the course, I found that the most uncomfortable topic for me to teach about was weight, and I did not know how to address students who were clearly larger than today's beauty norms allow. It seemed very difficult to lecture about and discuss the topic without in some way singling these students out, or in some way excluding them. I did not feel comfortable asking heavier students to talk about their own experiences, certainly not in the same way I might ask an Iranian student to explain the difference between Persians and Arabs. I thought a lot about the sources of my discomfort, sensing that there was a big gap between what I thought about weight and sexuality and how I 'felt' about it. Beauty ideals cannot simply be changed by changing the mind, because they are so deeply embodied. Realizing this gave me some traction in finding a way to talk about weight in a more productive way, without just saying that 'fat shaming' was wrong.

The second time I taught the course I decided the best way was to being the discussion of body size was with my own experience of weight. I was a thin person most of my life, and have only gained weight when middle-aged. In the previous five years I had gone from overweight to obese and diabetic. My body changed, but my attitudes about weight did not, and that disconnection, along with other changes that are a part of aging, shook my sense of self, challenged my masculinity and sexuality and caused a good deal of emotional 
pain. But because I gained weight as an adult, I did not experience anything like the trauma and rejection that goes along with being an overweight child and adolescent. I was able, though, to relate my own experiences as a very short child and adolescent - I was always very much shorter than my peers, in a masculine culture defined by sports. I was bullied and threatened, assaulted and humiliated simply because I was very short (a 'shrimp'), something I had no control over (not helped by the fact that I was such a wise-ass). The experience of social rejection based on appearance and embodiment left me with very conflicted attitudes towards others with deviant bodies and it obviously had something to do with my becoming an anthropologist.

I did not want to turn my classroom into a confessional, but I think opening up my own experiences made it much easier for all of us to discuss gendered and sexed bodies in class. ${ }^{4}$ But how to begin on such a difficult topic? I demonstrated by talking about the power of my gaze in the classroom, explaining that if I looked at the bigger students while I was lecturing, I could make them uncomfortable by making it seem that I was talking about them. But if I avoided looking at them, I was excluding them from the conversation, a form of shunning. I could then ask the students to think about how to deal with this dilemma.

I was very fortunate to have an assertive young African-American in the class, who immediately recognized that this was exactly the issue that left her feeling marginalized in classes where she was always a minority. As she said: "you did not want every class to be about race, even though race was part of every classroom". Even though she had by necessity become a sophisticated and quick judge of peoples' attitudes towards her blackness, she still started out every class with the same sense of distance and uncertainty. This turned the discussion away from difference, and towards the way that our experiences become embodied, the way we experience them emotionally and physically rather than just through logic and reason. This proved to be a vital element in our readings and discussion of fat shaming, fat liberation, dieting and diet culture, and attuned everyone to the subtle ways everyday speech and behavior are based on cultural assumptions about the desirable body.

Mimi Nichter's book Fat Talk (2001) proved to be an ideal bridge to move the discussion from the personal to the analytical (and eventually the political). The book helps them see how everyday conversations convey a close relationship between food, morality and femininity, while feeding insecurity and unhealthy practices like 'crashdieting'. This lesson is driven home by a short assignment which asks them to find examples of 'fat talk' in public speech and mass media, or in their dorms, sororities, or workplaces. The responses to this assignment have taught me that the kind of woman to woman 'fat talk' Nichter discusses has morphed and changed dramatically. In a world of social media, explicit and casual talk about beauty, sexuality and bodies has taken new forms, many of which I knew nothing about until I taught this course. When I asked the class to discuss the meanings of 'BBW' (Big Beautiful Women), a loud debate revolved around the question of whether mainstream gender stereotypes have really changed, or if resistant subcultures would always remain marginal. 5 I eventually brought this discussion around to the idea that pleasures and appetites can be a form of coercion and discipline bringing them directly to understanding of Foucault's work on structural violence, without turning the class over to several weeks on neo-marxism, cultural studies and French social theory.

The most challenging part of the class for me personally came when I had the students watch the film Precious by Lee Daniels (2009) about halfway through the se- 
mester, after we had discussed body image and cultural difference. This film brings together themes of oppression, sexual abuse, color and poverty in the story of a young black woman and her horrible mother. Food plays an important role in the story as both substance and symbol of oppression and liberation. I saw a lot of depth and complexity in the story, and thought it would emphasize my argument about the ambiguity of resistance in consumer culture, and open a discussion of the way we are all in some ways 'willing victims' of an oppressive system.

Instead most of the students hated the film and resisted the way I read it. Some felt offended and objected to having to watch it. Others found it boring, and could not see the connection with the class. Most of their written responses said the film was about willpower, and showed how you can escape from oppression if you are willing to work for it, a theme they found unconvincing. Even the brightest students did not really get the issues and points which I thought were prompted by the film, and they were cool and unconvinced by my argument.

The first time this happened I thought it could just be that particular class, so I tried again the second time I taught the course, only to meet the same reaction. How could I so misjudge their response? Is this just the distance created by age (after all I am 40 years older than most of them)? A failure like this is a caution about assuming too much, and a reminder that good teaching requires a kind of indirect ethnographic work on student life and culture. Each semester is an experiment with different methods of intervention and interpretation, so any course in Food, Sex and Gender will be as much a lesson to the teacher as it is to the student.

\section{Course Design}

The original pattern of the course was one lecture and one discussion each week, with several breaks for the students to talk about their individual research projects. I have not yet found a linear theme that would provide a logical order of topics for the semester, so instead I decided to start with my own individual and family relationships with food. First I assign them a short paper I published on the contrast between my wife's family meals and my own, and how it took many years for us to reach an accommodation for our own meals (Wilk 2006). Next they read Ruth Reichl's Tender at the Bone (2010), an engaging and personally revealing autobiography in which food plays a constant role. It is not hard for students to understand how Reichl's relationship with her mother was expressed and embodied through meals, and how she used food as a way to work through her own difficult relationships.

This book is also a good way to emphasize the specificity of history, since Reichl was closely involved with the $20^{\text {th }}$ century transplantation of French food to the USA. Later in the book food was the center of her participation in the counter-culture of the Bay area in the 1960s and early 70s. Then we follow the women's movements of the 1980s, when she develops a professional voice as a writer and critic. One of the most important themes in the book is the way food is both cause and consequence in her complicated and difficult relationship with her mother. While reading this book the students are starting to write their own narratives about food in their lives - material we use later in the semester when we discuss class, ethnicity and culture. I find this an effective way to teach the basic lessons of cultural relativism and ethnocentrism we always find unexpected diversity which puts their ideas of 'normal' in a different perspective.

Once the students are engaged with food as an intellectual project, my next step is to give them a short introduction to the basic theoretical tools used by anthropolo- 
gists in understanding food, from the evolutionary to the highly symbolic. Since the best way to learn theory is to apply it, I break the class up into sections and have each section use a different theory to analyze the same Egyptian meal. We use the same meal as a vehicle for a short history of food studies as an interdisciplinary field, and then some core readings on feminist food studies (Avakian and Haber 2005). I provoke students to think about why it has taken so long for gender and women's studies to engage with food, given that women in so many cultures are exclusively tasked with cooking, serving and cleaning up after meals.

My point in these readings, lectures and discussions is to show how a critical and reflexive approach to knowledge and research can help explain changing academic topics, and prompt students to think of 'blind spots' where important issues are missing or thinly covered. This introduces students to the importance of a sociology of knowledge, and it also primes them for their term paper assignments. They are looking for topics where there is not much research or publication, particularly in the area of food and sexuality. I urge them to pursue primary research for their projects, using advertisements, literature, visual art, mass media, cookbooks, trade journals, blogs, and academic literature. This assignment is so different from the usual term paper that I need to keep asking them to develop their topics, talking about them in class, with me in office hours, and with other students.

The following sections of the class take up the issue of food, embodiment, and particularly fatness. This is one of the few areas of the course where there is abundant popular, literary and academic material to use in teaching. To make the key anthropological point that beauty and sexiness are culturally constructed, we start out reading Rebecca Popenoe's monograph Feeding Desire (2003). This is a sensitive study of Moors in northeastern Africa, a culture that reveres fatness as a sign of female beauty, and young women, and girls are still 'fattened up' to make them desirable. We also talk about the Lodabba in northern Ghana, where men get dressed up and use elaborate make-up, so women will find them beautiful, and choose them as husbands. I discuss my own work in Belize on beauty pageants, ideal body types, and the conflict between local and global standards. I use this to make the specific point that sexiness in many parts of the world is not as 'visual' as in the USA; that in Belize public performance is much more important for both men and women than physical appearance.

The more general point here is about commensality, the power of sharing food production and consumption. Our first social relationship in life is created by feeding at the breast or bottle, and the foods we eat together literally creates our social bodies. But given all the reasons why food consumption is so essential in the creation of our gendered bodies, why is this such a blank spot in the university curriculum? To dramatize this point, I give an overnight assignment asking students to search the web for syllabi at other universities that connect food with gender or sexuality, and more broadly with class and power.

I devote the second half of the class to a sequence of topical discussions, starting with the importance of gender in food production and trade. Deborah Barndt's work (2007) on the exploitation of women in tomato production connects with other ways that women are oppressed through violence and gender norms. This topic can be an opening to the gender activism of international groups like Other Worlds and La Via Campesina, and local groups like women's shelters and food banks. It can also be an entry into the concepts of food sovereignty and food security, and controversies over infant feeding and the unequal effects of diet on adult health.

As I mentioned above, it is very hard to find good research on sexuality and food, 
and it is a bit shocking to find so little social sciences on topics like aphrodisiacs and sexual food play. In The Pornography of $\mathrm{Me}^{-}$ at, the Sexual Politics of Meat, and many other popular works Carol Adams (1990) has presented one of the few sustained arguments about food and sexuality. Adams claims that feminism requires vegetarianism, and eating meat is a form of brutality grounded in male identity. She equates killing and eating animals with male violence against women, and looks to Christian and feminist traditions of healing and non-violence for an alternative. Adams is a regular and popular lecturer on college campuses.

Historians tell us that vegetarianism in Europe and North America has a deep historical connection with radical movements for woman's suffrage, abolitionism, and pacifism and it is helpful to see Adams' work in this tradition. In class I ask why her ideas are so appealing, rather than setting out to debunk them. Students find many of the logical flaws of her argument, but they still feel sympathy with it, and they cannot deny the power of the images she uses in her books and lectures. By this point in the semester they have found other ways to connect food with gender and sexuality that are more logical and plausible. From the beginning of the class we have talked about the historical reasons why meat has been associated with masculinity, and they have also been exposed to other cultures which do not gender classify foods in this particular way.

I can see many topics that could fit into the second half of this course, depending on the interests of instructors and students. In 2014 I added a section on female farmers in the USA, and invited a local farmer to come and talk about her experiences. I also like to teach about my own historical research on the diets of 'manly men' in the extractive industries of the Americas. There is now enough literature to have a section on queering food and there are many popular sources on LGBT food and identity that students can research on the internet. In the future I would like to develop a section of the course on 'Food Porn,' which is a popular but poorly defined concept, related to food hacking, biohacking, fermentation, foraging, gleaning, freeganism, urban agriculture, open source food and other new trends in the online food community, all of which have unvoiced gendering.

\section{Conclusions AND CONFESSIONS}

The student rosters in my food classes at Indiana University reflect the profound gendering of the topic; there are usually 8 10 female students for every male. The first time I taught FSG in the spring semester of 2009-10, 26 women and two men enrolled, a ratio that was typical in other gender studies courses, but more skewed than my food classes taught in anthropology, where we have a number of male graduate and undergraduates students seeking minor, as well as graduate students in our Food Studies $\mathrm{PhD}$ track. ${ }^{6}$

Colleagues tell me that they see a lot more men in food classes that are concerned with sustainability, food production and environmental issues, which again reflects the dominant gendered division of labor. I often call attention to gender imbalance in the classroom in the very first class meeting, as a way to explain the substance of the course. In that first meeting I also show slides of different foods, asking them to say whether they think of the food as male or female; some examples (hamburger, sliced turkey breast) are clear to everyone, while others, such as hot dogs and diet soft drinks evoke a fertile disagreement, particularly when the class includes international and minority students. This is also a good time to point out that there is a clear difference between the real and the ideal, since many women love beef, and men eat a lot of green salads and turkey. I find it particularly interesting when stu- 
dents say that particular brands of beverages, ingredients and fast food are gendered, so the class might discuss which brands (or types) of beer or alcohol are more feminine or masculine. Even in the first class, students have no trouble gendering cocktails, and identifying some kinds of eating as gay or butch.

It is disappointing that despite the broadened appeal of cooking and eating among our students, men are still afraid to take food-related classes at Indiana University. This may just be a reflection of Indiana's overall conservatism, but on the other hand, men are still dominant everywhere in restaurant kitchens, as celebrity chefs, and in writing for the mass media. Surveys show that domestic cooking chores are more evenly divided in American homes, but this is mostly because women are cooking less rather than men cooking more. There are encouraging signs in the business world, but the food studies classroom is still full of gendered but unspoken issues. I have just not been able to figure out a way to get more men into my classes.

I also have to admit that teaching FSG has been much more stressful and difficult than my other classes, but it is also more exciting and engaging. There is no question that food, sex and gender can be a volatile combination in the classroom, and any instructor has to be very clear about the boundaries of acceptable language and debate. It is often hard to define the point where theory collides with deeply held and embodied beliefs, where questioning a student becomes a form of harassment, and how and when to use the teacher's authority. This can be especially difficult when there are gender, age, and cultural differences among students, and between the students and the instructor. There are no simple answers for any of these issues, and as I said above, every class can become a voyage into terra incognita.

Nevertheless, I believe it is worth taking up the challenge. The breadth and immedi- acy of the class subject allows for a great deal of freedom in following connections, exploring new topics, and tracing contemporary trends and fashions. You will certainly learn a lot of new things about your students, their engagement with social media and about today's popular culture ( so- $^{-}$ me of which you may not want to know). You will also find yourself thinking about your own past, at the ways that our sexuality and gendering have always been closely intertwined with the things we put in our mouths.

\section{LITERATURE}

- Adams, Carol J. (1990): The Sexual Politics of Meat. Continuum, London/New York.

- Avakian, Arlene V. and Haber, Barbara (2005):

From Betty Crocker to Feminist Food Studies. University of Massachusetts Press, Massachusetts.

- Barndt, Deborah (2007): Tangled Route.

Rowman \& Littlefield Publishers, Lanham.

Nitcher, Mimi (2001): Fat Talk. Havard University Press, Havard.

- Popenoe, Rebecca (2003): Feeding Desire. Routledge, New York.

- Reichl, Ruth (2010): Tender at the Bone. Random House, New York.

. Wilk, Richard (2006): Serving or Helping Yourself at the Table, in: Food, Culture and Society. 2006/9.

\section{Notes}

1. The online urban dictionary even defines the term 'food sex' to mean 'an orgasmic feast.' http://www.urbandictionary.com/define.php?ter $\mathrm{m}=$ food + sex

2. In marketing, segmentation (sometimes called demographics) is the process of dividing markets into social and geographical sub-groups that can be individually targeted. This is often a strategy to introduce new products by finding the groups most likely to be the first to buy or use the product, becoming 'trend leaders.' Zip codes are often used to show the geographic distribution of the many market segments. 
3. For example energy drinks, earplugs and chocolate eggs, see twentytwowords.com/ridiculouslygendered-products/

4. I have discussed gender in my classrooms for many years, because conversational norms disadvantage women in classroom discussions. I use the work of linguists Robin Lakoff and Deborah Tannen to explain how completely unconscious norms make it difficult for even the loudest women to be heard.

5. The student body at IU is still remarkably white and Midwestern; teaching this class in a more diverse setting could be very different.

6. At IU we have 16-week semesters with $150 \mathrm{mi}$ nutes of class time each week, plus one exam week. While this class was taught in gender studies, I now teach FSG in anthropology, as part of our undergraduate minor in food anthropology. I allow several graduate students into the class, and hold a separate weekly graduate discussion section for them. 